\title{
Type I diabetes mellitus does not alter initial splanchnic glucose extraction or hepatic UDP-glucose flux during enteral glucose administration
}

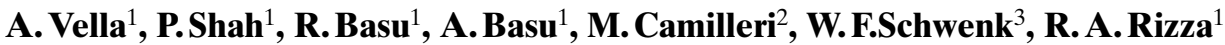 \\ ${ }^{1}$ Department of Internal Medicine, Division of Endocrinology, Metabolism and Nutrition, Mayo Clinic and Foundation, \\ 200 1st Street SW, Room 5-194 Joseph, Rochester, Minnesota, USA \\ ${ }^{2}$ Department of Internal Medicine, Division of Gastroenterology, Mayo Clinic and Foundation, Rochester, Minnesota, USA \\ ${ }^{3}$ Department of Pediatrics and Adolescent Medicine, Mayo Clinic and Foundation, Rochester, Minnesota, USA
}

\section{Abstract}

Aims/hypothesis. Our aim was to determine whether an alteration in splanchnic glucose metabolism could contribute to postprandial hyperglycaemia in people with Type I (insulin-dependent) diabetes mellitus.

Methods. Splanchnic glucose extraction, hepatic glycogen synthesis and endogenous glucose production were compared in 8 Type I diabetic patients and in 11 control subjects. Endogenous hormone secretion was inhibited with somatostatin while insulin $(\sim 550$ $\mathrm{pmol} / \mathrm{l})$ and glucagon $(\sim 130 \mathrm{ng} / \mathrm{l})$ concentrations were matched with exogenous hormone infusions. Glucose containing $\left[3-{ }^{3} \mathrm{H}\right]$ glucose was infused into the duodenum at a rate of $20 \mu \mathrm{mol} \cdot \mathrm{kg}^{-1} \cdot \mathrm{min}^{-1}$. Plasma glucose concentrations were maintained at about $8.5 \mathrm{mmol} / 1$ in both groups by means of a separate variable intravenous glucose infusion.

Results. Initial splanchnic glucose uptake, calculated by subtracting the systemic rate of appearance of [3$\left.{ }^{3} \mathrm{H}\right]$ glucose from the rate of infusion of $\left[3-{ }^{3} \mathrm{H}\right]$ glucose into the duodenum, did not differ in the diabetic and non-diabetic patients $(4.1 \pm 0.8$ vs $3.0 \pm 1.0 \mu \mathrm{mol} / \mathrm{kg} /$ min). In addition, hepatic glycogen synthesis, measured using the acetaminophen glucuronide method did not differ $(10.7 \pm 2.4$ vs $10.1 \pm 2.7 \mu \mathrm{mol}$. $\left.\mathrm{kg}^{-1} \cdot \min ^{-1}\right)$. On the other hand, suppression of endogenous glucose production, measured by an intravenous infusion of $\left[6,6-{ }^{2} \mathrm{H}_{2}\right]$ glucose, was greater $(\mathrm{p}<0.05)$ in the diabetic than in the non-diabetic subjects $\left(1.7 \pm 1.6\right.$ vs $\left.5.8 \pm 1.9 \mu \mathrm{mol} \cdot \mathrm{kg}^{-1} \cdot \mathrm{min}^{-1}\right)$.

Conclusion/interpretation. When glucose, insulin and glucagon concentrations are matched in individuals with relatively good chronic glycaemic control, Type I diabetes does not alter initial splanchnic glucose uptake of enterally delivered glucose or hepatic glycogen synthesis. Alterations in splanchnic glucose metabolism are not likely to contribute to postprandial hyperglycaemia in people with well controlled Type I diabetes. [Diabetologia (2001) 44: 729-737]

Keywords Splanchnic glucose metabolism, Type I diabetes mellitus, Postprandial hyperglycaemia, Acetaminophen glucuronide, Hepatic glycogen synthesis
Poorly controlled Type I (insulin-dependent) diabetes mellitus is characterized by both fasting and postprandial hyperglycaemia. Both need to be corrected if glucose concentrations are to be fully restored to

Received: 10 November 2000 and in revised form: 22 January 2001

Corresponding author: R. A. Rizza, M.D., Mayo Foundation, 200 I $^{\text {st }}$ Street SW, Room 5-194 Joseph, Rochester, MN 55905, USA

Abbreviations: UDP, Uridine diphosphate; UDP glucose, Uridine diphosphoglucose; GLP-1, Glucagon-like peptide-1. concentrations present in non-diabetic humans. Regulation of glucose concentration after ingestion of a carbohydrate containing meal is complex. The ingested carbohydrate must first be digested to a monosaccharide by a series of enzymatic steps. In the case of glucose, this monosaccharide is then transported into the enterocyte by a sodium dependent glucose transporter [1]. Subsequently, it is transported out of the enterocyte into the portal vein by a Glut 2 transporter whose uptake increases in parallel with rises in glucose over the physiological concentration range $[2,3]$. Studies in both animals and humans indicate that only 75 to $80 \%$ of enterally delivered glucose 
reaches the portal vein. Assuming complete absorption of enterally delivered glucose, this implies substantial consumption of glucose by the intestine [47]. Once glucose reaches the portal venous circulation, some glucose is extracted by the liver and phosphorylated to glucose-6-phosphate by hepatic glucokinase $[8,9]$. The rate of hepatic glucose extraction is dependent on a variety of factors with the prevailing glucose and insulin concentrations being two of the most important [10-13]. The resultant glucose-6phosphate could then be either incorporated into glycogen (by the direct or indirect pathways), degraded to three carbon fragments, or dephosphorylated by glucose-6-phosphatase back to glucose which in turn can be released into the hepatic vein [14]. The amount of glucose that must be disposed of by peripheral tissues during the postprandial period equals the sum of that derived from endogenous sources (i.e. glycogenolysis and gluconeogenesis) and the portion of the ingested glucose that is not extracted by the splanchnic bed.

There is limited information on the effects of Type I diabetes on splanchnic glucose extraction. In a series of experiments, investigators used nuclear magnetic resonance spectroscopy to demonstrate that hepatic glycogen synthesis after ingestion of a mixed meal was markedly impaired in people with poorly controlled Type I diabetes [15]. In contrast, the same group of investigators subsequently showed that rates of hepatic glycogen synthesis did not differ in subjects with Type I diabetes and in non-diabetic subjects during intravenous glucose infusion when glucose and insulin concentrations were matched using the hyperglycaemic, hyperinsulinaemic clamp technique [16]. A similar conclusion was reached by others in pancreatectomized rats, an animal model of Type I diabetes [11].

Although the latter two experiments provide important mechanistic insights into the regulation of hepatic glucose metabolism during intravenous infusion of glucose, their applicability to events that occur when glucose is delivered enterally, (e.g. after carbohydrate ingestion), is less certain. Relative insulin deficiency almost certainly contributed to lower rates of postprandial hepatic glucose uptake in the earlier experiments. [15]. This does not, however, exclude a defect in the "portal" signal that normally enhances glucose uptake when glucose is delivered either enterally or into the portal vein $[17,18]$. Furthermore, these experiments do not provide insight as to whether increased intestinal glucose absorption, decreased intestinal or hepatic glucose extraction or a combination of all three contribute to postprandial hyperglycaemia in subjects with diabetes. If so, this would be consistent with studies in animals where diabetes has been shown to be associated with hypertrophy of the intestinal mucosa, an increase in intestinal glucose transport and decreased hepatic glucose uptake $[19,20]$.
In an effort to address these questions, our experiments sought to determine whether splanchnic glucose metabolism is altered in people with Type I diabetes mellitus. Thus, splanchnic extraction of intraduodenally infused glucose was measured using a dual tracer approach [21-23]. Flux through the UDP glucose pool (an index of hepatic glycogen synthesis) was measured using the acetaminophen glucuronide method [24-28] in subjects with Type I diabetes and in non-diabetic subjects. Somatostatin was infused along with replacement amounts of glucagon and growth hormone so as to keep portal venous hormone concentrations constant and equal in both groups. Insulin concentrations were increased to approximately $550 \mathrm{pmol} / \mathrm{l}$ while glucose concentrations were clamped at about $8.5 \mathrm{mmol} / \mathrm{l}$ by supplemental intravenous glucose infusion.

\section{Subjects and methods}

Subjects. With the approval given by the Mayo Institutional Review Board, 8 patients with Type I diabetes and 11 non-diabetic subjects matched for age and weight gave informed written consent to participate in the study (Table 1). All subjects were in good health and at a stable weight. None of them did vigorous physical exercise regularly. Before participating, all subjects completed a validated bowel disease questionnaire to ensure that they had no gastrointestinal symptoms [29]. The mean $\mathrm{HbA}_{1 \mathrm{c}}$ of the patients with Type I diabetes was $7.5 \pm 0.5 \%$ (normal range 4.0 to $6.3 \%$ ). Of the patients with Type I diabetes 3 of the 8 were treated with continuous subcutaneous insulin infusion and the remaining 5 were treated with multiple daily injections of insulin. Long-acting insulin was discontinued on the evening of admission prior to each study.

Each subject was studied on two occasions. On one occasion, the diabetic patients were infused with Glucagon-like peptide-1 (GLP-1) as part of a separate protocol and on the other occasion they were infused with saline. Similarly, as part of a separate protocol, on one occasion the non-diabetic subjects received no glucose through the nasal duodenal tube whereas on the second occasion the non-diabetic subjects were given glucose through the nasal duodenal tube. By design, the order of the study was random and the diabetic and non-diabetic subjects were studied concurrently to enable comparison between groups.

Experimental Design. All subjects were admitted to the Mayo Clinic General Clinical Research Center at 1800 hours, the evening before the study. After ingestion of a standard $10 \mathrm{Kcal} / \mathrm{kg}$ meal (55\% carbohydrate, $30 \%$ fat, and $15 \%$ protein), subjects fasted until the end of the study. An 18-gauge cannula was inserted into each forearm after the meal. Human insulin (0.1 unit/ml Humulin R, Eli Lilly, Indianapolis, Ind., USA) was then infused in an amount sufficient to maintain euglycaemia throughout the night in the patients with Type I diabetes [30].

At 0600 hours $(-120 \mathrm{~min})$ the next morning, subjects were taken to the fluoroscopy unit where an 8 French Flexiflo enteral feeding tube (Ross Laboratories, Columbus, Ohio, USA) was passed under fluoroscopic guidance through the nasopharynx into the fourth part of the duodenum. The average duration of tube placement was $15 \mathrm{~min}$ with an average fluoroscopy 
time of less than $2 \mathrm{~min}$. The subjects were then returned to the clinical research centre. At 0745 hours, subjects were asked to void after which two grams of acetaminophen suspension was given over approximately $3 \mathrm{~min}$ through the nasoduodenal tube. Urine was then collected for the duration of the study to allow measurement of urinary acetaminophen glucuronide as described previously [31].

At 0730 hours, an 18-gauge cannula was inserted in a retrograde fashion into a dorsal hand vein. The hand was then placed in a heated box in order to obtain arterialized venous blood samples. At 0800 hours $(0 \mathrm{~min})$ a constant $\left(20 \mu \mathrm{mol} \cdot \mathrm{kg}^{-1}\right.$. $\mathrm{min}^{-1}$ ) infusion of glucose containing $\left[3-{ }^{3} \mathrm{H}\right]$ glucose (New England Nuclear, Boston, Mass., USA), at a specific activity of $599 \pm 37 \mathrm{dpm}$ per $\mu \mathrm{mol}$ glucose was started through the nasoduodenal tube. Intravenous infusions of insulin $(6 \mathrm{pmol}$. $\left.\mathrm{kg}^{-1} \cdot \mathrm{min}^{-1}\right)$, somatostatin $\left(60 \mathrm{ng} \cdot \mathrm{kg}^{-1} \cdot \mathrm{min}^{-1}\right)$, human growth hormone $\left(3 \mathrm{ng} \cdot \mathrm{kg}^{-1} \cdot \mathrm{min}^{-1}\right)$, glucagon $\left(0.65 \mathrm{ng} \cdot \mathrm{kg}^{-1} \cdot \mathrm{min}^{-1}\right)$, $\left[6,6-{ }^{2} \mathrm{H}_{2}\right]$ glucose $\left(33 \mu \mathrm{mol} / \mathrm{kg}\right.$ prime; $0.33 \mu \mathrm{mol} \cdot \mathrm{kg}^{-1} \cdot \mathrm{min}^{-1}$ constant, Masstrace, Woburn, Mass., USA) and $\left[{ }^{14} \mathrm{C}\right]$ galactose $(15 \mu \mathrm{Ci}$ prime; $0.15 \mu \mathrm{Ci} / \mathrm{min}$ constant; New England Nuclear) also were started at 0800 hours. Beginning at time zero, additional glucose (enriched with $\left[6,6-{ }^{2} \mathrm{H}_{2}\right]$ glucose) was infused intravenously in amounts sufficient to maintain plasma glucose concentration at about $8.5 \mathrm{mmol} / \mathrm{l}$. The rate of the "basal" intravenous $\left[6,6-{ }^{2} \mathrm{H}_{2}\right]$ glucose infusion was altered in an effort to approximate the anticipated pattern of decreasing glucose production and thereby maintain plasma glucose specific activity constant: (0-30 min, 100\% ; 31-60 min, 86\% ; 61-90 min, 62\%; 91-120 min, 46\% ; 121-150 min, 38\% ; 151-180 min, $30 \%$; 181-210 min, 26\%; 211-240 min, $24 \%$ ) [32].

Analytical techniques. Arterialized plasma samples were placed in ice, centrifuged at $4{ }^{\circ} \mathrm{C}$, separated, and stored at $-20^{\circ} \mathrm{C}$ until assayed. Plasma glucose concentrations were measured using a glucose oxidase method (Yellow Springs Instrument, Yellow Springs, Ohio, USA). Plasma cortisol and growth hormone concentrations were measured using a chemiluminescence assay with reagents obtained from Beckman (Access Assay, Beckman, Chaska, Minn., USA). Plasma glucagon and C-peptide concentrations were measured by radioimmunoassay (Linco Research, St. Louis, Mo., USA). Because of the presence of insulin antibodies in three of the subjects with Type I diabetes, plasma insulin concentrations in all subjects were measured after precipitation with polyethylene glycol (Access Assay, Beckman). Body composition was measured using dual-energy Xray absorptiometry (DEXA scanner, Hologic, Waltham, Mass., USA). Plasma $\left[3-{ }^{3} \mathrm{H}\right]$ glucose specific activity was measured using liquid scintillation counting [33]. Urinary $\left[{ }^{14} \mathrm{C}\right]$ glucuronide specific activity was measured using high performance liquid chromatography [31]. Plasma [6, 6- $\left.{ }^{2} \mathrm{H}_{2}\right]$ glucose enrichment was measured by Gas Chromatography Mass Spectrometry [34]. $\mathrm{HbA}_{1 \mathrm{C}}$ was measured by affinity chromatography (Gly-Affin; Isolab, Akron, Ohio, USA).

Calculations. Glucose appearance and disappearance $\left(\mathrm{R}_{\mathrm{d}}\right)$ was calculated using the steady state equations [35]:

$\mathrm{R}_{\mathrm{d}}=\mathrm{R}_{\mathrm{a}}=\frac{\mathrm{F}\left[\mathrm{D}_{\text {2glu }}\right]}{\operatorname{MPE}\left[6,6-{ }^{2} \mathrm{H}_{2}\right] \text { glucose }}-\mathrm{F}\left[\mathrm{D}_{2 \mathrm{glu}}\right]$

where $F[D 2 g l u]$ is the intravenous infusion rate of $\left[6,6-{ }^{2} \mathrm{H}_{2}\right]$ tracer and MPE $\left[6,6-{ }^{2} \mathrm{H}_{2}\right]$ glucose is the plasma enrichment of $\left[6,6-{ }^{2} \mathrm{H}_{2}\right]$ glucose.

The systemic rate of appearance of intraduodenally infused $\left[3^{-3}\right]$ glucose (Duodenal Ra) was calculated as:

Duodenal $\left[3-{ }^{3} \mathrm{H}\right]$ glucose $\mathrm{R}_{\mathrm{a}}=\frac{\mathrm{F}\left[\mathrm{D}_{\text {2glu }}\right]}{\left[6,6^{2} \mathrm{H}_{2}\right] \text { glucose } /\left[3-{ }^{3} \mathrm{H}\right] \text { glucose }}$ where $\left[6,6-{ }^{2} \mathrm{H}_{2}\right]$ glucose is the concentration of $\left[6,6-{ }^{2} \mathrm{H}_{2}\right]$ glucose in plasma and $\left[3-{ }^{3} \mathrm{H}\right]$ glucose is the concentration of $[3-$ $\left.{ }^{3} \mathrm{H}\right]$ glucose in the plasma.

The systemic rate of appearance of intraduodenally infused glucose (Duodenal Ra) was calculated by dividing the systemic rate of appearance (in $\mathrm{dpm} / \mathrm{min}$ ) of the intraduodenally infused $\left[3-{ }^{3} \mathrm{H}\right]$ glucose by the specific activity of the intraduodenally infused glucose:

Duodenal $\mathrm{Ra}=\frac{\text { Duodenal Tracer Ra }\left[3-{ }^{3} \mathrm{H}\right] \text { glucose }}{\text { Duodenal } \mathrm{SA}\left[3-{ }^{3} \mathrm{H}\right] \text { glucose }}$

where Duodenal SA $\left[3-{ }^{3} \mathrm{H}\right]$ glucose is the ratio of $\left[3-{ }^{3} \mathrm{H}\right]$ glucose to glucose in the duodenally infused glucose.

Endogenous glucose production was calculated by subtracting the sum of the rate of the intravenous glucose infusion and the systemic rate of appearance of intraduodenally infused glucose from the rate of glucose appearance.

Endogenous glucose production $=\mathrm{Ra}-\mathrm{F}[\mathrm{D} 2 \mathrm{glu}]-$ Duodenal $\mathrm{Ra}$

Initial splanchnic glucose uptake (ISGU) was calculated by subtracting the systemic rate of appearance of the intraduodenally infused glucose from the intraduodenal glucose infusion rate:

ISGU $=\mathrm{G}_{\text {duod }}-$ Duodenal $\mathrm{R}_{\mathrm{a}}$

where $G_{\text {duod }}$ is the rate of infusion of intraduodenal glucose. Percent initial splanchnic glucose extraction was calculated by dividing ISGU by $\mathrm{G}_{\mathrm{duod}}$ and multiplying by 100 :

Splanchnic Extraction Ratio $=\frac{I S G U}{G_{\text {duod }}} \times 100$

Flux through the uridine-diphosphate-(UDP)-glucose pool was calculated as:

UDP glucose flux $=\frac{\mathrm{F}_{\mathrm{GAL}}}{\mathrm{SA} \text { of UDP }\left[{ }^{14} \mathrm{C}\right] \text { glucose }}$

where $\mathrm{F}_{\mathrm{GAL}}$ is the intravenous infusion rate of $\left[{ }^{14} \mathrm{C}\right]$ galactose and SA of UDP $\left[{ }^{14} \mathrm{C}\right]$ glucose is the specific activity of acetaminophen $\left[{ }^{14} \mathrm{C}\right]$ glucuronide in the urine $[25,26,36,37]$. The assumptions and limitations of this technique have been discussed in detail previously[31].

Statistical Analysis. Data in the text and figures are expressed as means \pm SEM. Rates of infusion and turnover are expressed as $\mu$ mol per kilogram of lean body mass per min. The rates obtained during the last half-hour of the study were averaged and used for statistical analysis. Student's two-tailed non-paired $t$ test was used to test the hypothesis that Type I diabetes mellitus alters splanchnic glucose metabolism. A $p$ value of less than 0.05 was considered to be statistically significant.

\section{Results}

Plasma, glucose, insulin and C-peptide concentrations. Glucose concentrations (Fig.1, upper panel) before the study were slightly but not significantly higher in the diabetic than non-diabetic subjects $(6.8 \pm 1.4$ vs $5.2 \pm 0.1 \mathrm{mmol} / \mathrm{l})$. The combined intraduodenal and intravenous glucose infusions resulted in a prompt increase in plasma glucose 

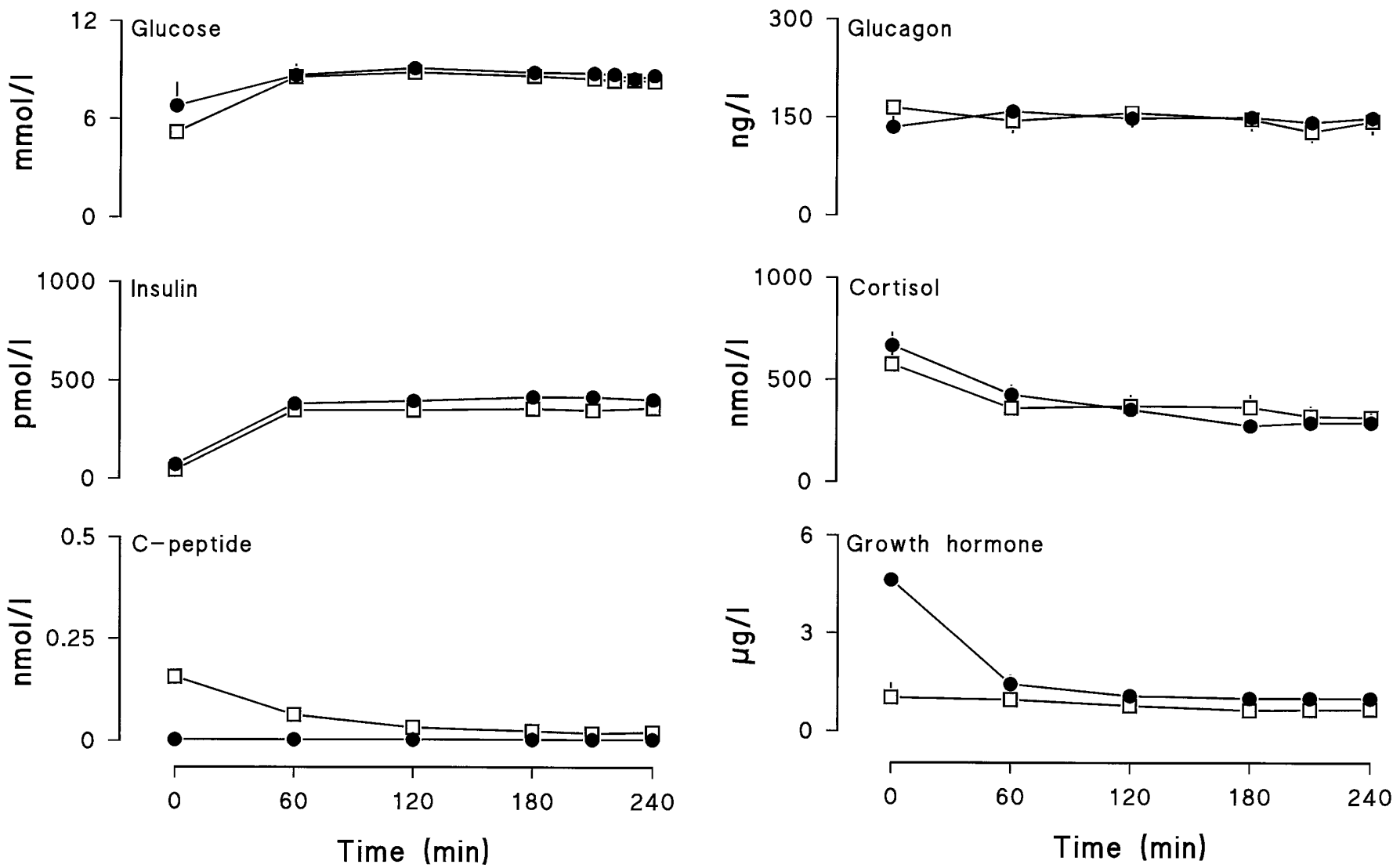

Fig. 1. Plasma glucose, insulin and C-peptide concentrations observed during the study. Solid circles $(\bullet)$ represent diabetic subjects and the non-diabetic subjects are represented by open squares $(\square)$

concentration to values that did not differ in the diabetic and non-diabetic subjects $(8.4 \pm 0.2$ vs $8.7 \pm 0.2 \mathrm{mmol} / \mathrm{l})$.

Plasma insulin concentrations (Fig.1, middle panel) were slightly but not significantly higher in the diabetic than non-diabetic subjects before the study $(186 \pm 98$ vs $95 \pm 36 \mathrm{pmol} / \mathrm{l})$ and did not differ during the study $(557 \pm 88$ vs $536 \pm 94 \mathrm{pmol} / \mathrm{l})$. C-peptide concentrations were not detectable in all volunteers with Type I diabetes both before and during the study (Fig. 1, lower panel). Somatostatin resulted in prompt suppression of C-peptide in non-diabetic subjects to concentrations that no longer differed from 120 min onwards from those observed in the diabetic subjects.

Glucagon, cortisol and growth hormone concentrations. Glucagon concentrations (Fig.2, upper panel) did not differ in the diabetic patients and non-diabetic subjects either before $(137 \pm 9$ vs $129 \pm 8.0 \mathrm{pmol} / \mathrm{l})$ or during the study $(148 \pm 11$ vs $143 \pm 10 \mathrm{pmol} / \mathrm{l})$. Cortisol concentrations did not differ in the diabetic patients and non-diabetic subjects before the study period and decreased equally in both groups during the study (Fig.2, middle panel). Growth hormone

Fig. 2. Plasma glucagon, cortisol and growth hormone concentrations observed during the study. Solid circles $(\bullet)$ represent diabetic subjects and the non-diabetic subjects are represented by open squares $(\square)$

concentrations (Fig.2, bottom panel) were slightly higher in the diabetic patients than in the non-diabetic subjects before the study $(4.1 \pm 1.9$ vs $2.5 \pm 0.9 \mu \mathrm{g} / \mathrm{l}$, $p=0.43)$ and decreased to comparable values during the study $(1.0 \pm 0.1 \mathrm{vs} 1.0 \pm 0.1 \mu \mathrm{g} / \mathrm{l})$.

Intravenous and intraduodenal glucose infusion rates. The intraduodenal glucose infusion rates $(19.8 \pm 0.4$ vs $\left.21.0 \pm 0.3 \mu \mathrm{mol} \cdot \mathrm{kg}^{-1} \cdot \mathrm{min}^{-1}\right)$ and the intravenous glucose infusion rates $(51.7 \pm 5.7$ vs $54.2 \pm$ $4.8 \mu \mathrm{mol} \cdot \mathrm{kg}^{-1} \cdot \mathrm{min}^{-1}$ ) necessary to maintain plasma glucose concentrations at target values were comparable in the diabetic patients and non-diabetic subjects (Fig. 3).

Plasma $\left[6,6^{2} \mathrm{H}_{2}\right]$ glucose enrichment and ratio of [6, 6-2 $\left.\mathrm{H}_{2}\right]$ glucose to $\left[3-{ }^{3} \mathrm{H}\right]$ glucose. Intravenous glucose infusion resulted in a prompt increase in plasma [6, 6${ }^{2} \mathrm{H}_{2}$ ] glucose enrichment (used to trace endogenous glucose production and glucose disappearance) in both groups to values that approximated steady state within $120 \mathrm{~min}$ (Fig. 4, upper panel). The intraduodenal infusion of $\left[3-{ }^{3} \mathrm{H}\right]$ glucose resulted in a slightly slower increase in plasma $\left[3-{ }^{3} \mathrm{H}\right]$ glucose concentration and this resulted in a transient but comparable 

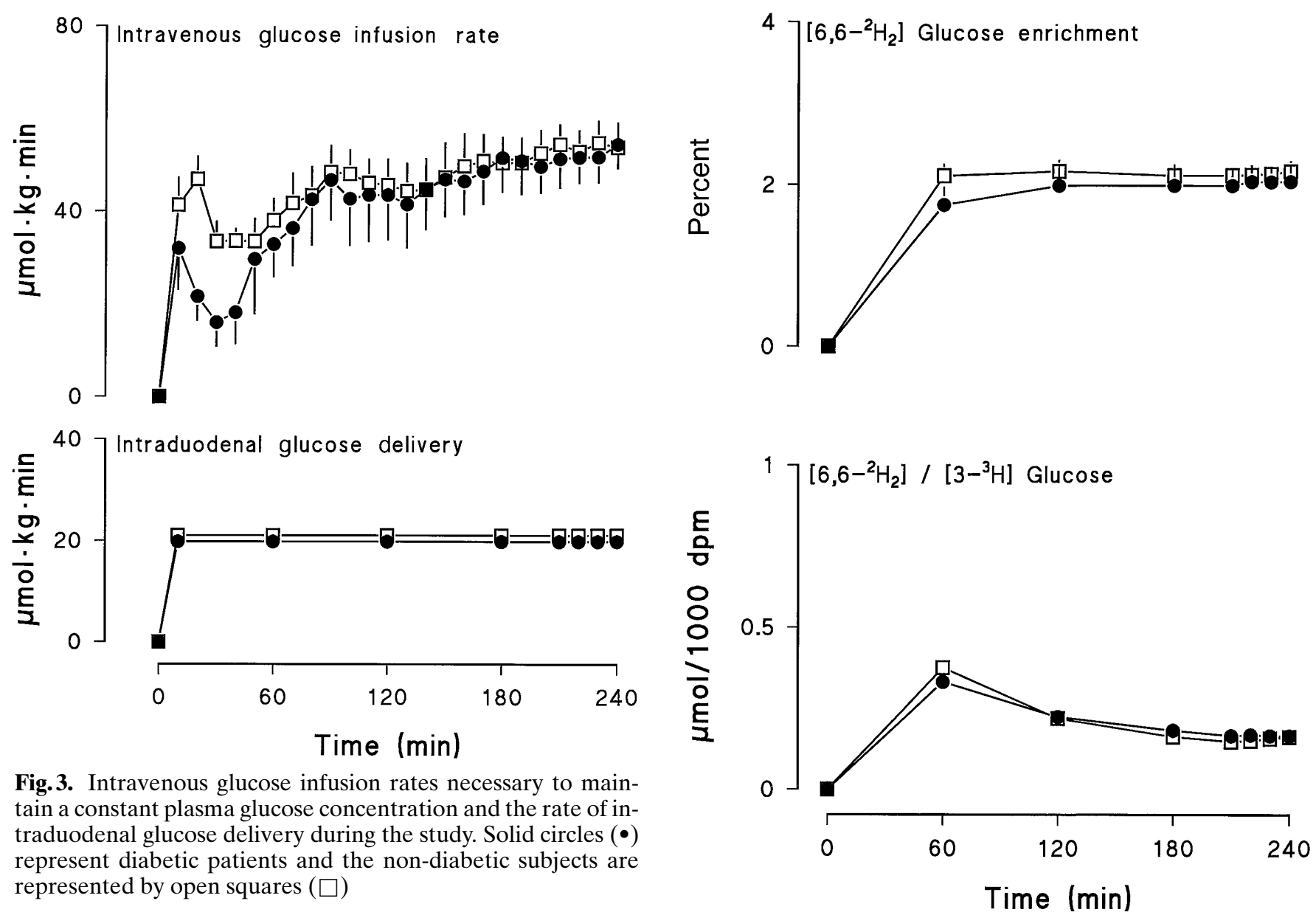

Fig. 3. Intravenous glucose infusion rates necessary to maintain a constant plasma glucose concentration and the rate of intraduodenal glucose delivery during the study. Solid circles $(\bullet)$ represent diabetic patients and the non-diabetic subjects are represented by open squares $(\square)$

increase in the plasma ratio of $\left[6,6-2 \mathrm{H}_{2}\right]$ glucose to $\left[3-{ }^{3} \mathrm{H}\right]$ glucose (used to trace the systemic rate of appearance of intraduodenally infused glucose) in both groups. This ratio fell comparably in both groups approximating steady state within $180 \mathrm{~min}$ (Fig. 4, lower panel).

Endogenous glucose production and glucose disappearance. Endogenous glucose production during the final $30 \mathrm{~min}$ of the study was completely suppressed in the diabetic patients $(1.2 \pm 1.2 \mu \mathrm{mol}$. $\left.\mathrm{kg}^{-1} \cdot \mathrm{min}^{-1}\right)$ and was nearly completely suppressed in the non-diabetic subjects $\left(4.1 \pm 0.7 \mu \mathrm{mol} \cdot \mathrm{kg}^{-1}\right.$. $\left.\min ^{-1}\right)$. This resulted in rates of endogenous glucose production that were slightly lower $(p<0.05)$ in the diabetic patients than in the non-diabetic subjects (Fig. 5, upper panel). Glucose disappearance (Fig.5, lower panel) during the final $30 \mathrm{~min}$ of the study did not differ in the diabetic patients and non-diabetic subjects $\left(68.0 \pm 5.2\right.$ vs $\left.75.3 \pm 4.8 \mu \mathrm{mol} \cdot \mathrm{kg}^{-1} \cdot \mathrm{min}^{-1}\right)$.

Initial splanchnic glucose uptake and splanchnic extraction ratio. The systemic rate of appearance of the intraduodenally infused glucose during the final 30 min of the study (Fig. 6, upper panel) was comparable in the diabetic patients and non-diabetic sub-

Fig. 4. Plasma $\left[6,6-{ }^{2} \mathrm{H}_{2}\right]$ glucose enrichment and the ratio of $[6$, $\left.6-{ }^{2} \mathrm{H}_{2}\right]$ glucose to $\left[3-{ }^{3} \mathrm{H}\right]$ glucose observed during the study. Solid circles $(\bullet)$ represent diabetic patients, whereas the non-diabetic subjects are indicated by open squares $(\square)$

jects $\left(15.2 \pm 0.79\right.$ vs $\left.17.5 \pm 0.7 \mu \mathrm{mol} \cdot \mathrm{kg}^{-1} \cdot \mathrm{min}^{-1}\right)$. This resulted in comparable rates of both initial splanchnic glucose uptake $(4.6 \pm 0.7$ vs $3.6 \pm$ $\left.0.8 \mu \mathrm{mol} \cdot \mathrm{kg}^{-1} \cdot \mathrm{min}^{-1}\right)$ and percent splanchnic glucose extraction $\left(23.1 \pm 3.5 \mathrm{vs} 17.0 \pm 3.4 \mu \mathrm{mol} \cdot \mathrm{kg}^{-1} \cdot \mathrm{min}^{-1}\right)$ in the diabetic patients and non-diabetic subjects (Fig. 6, middle, lower panels).

UDP-glucose flux. UDP-glucose flux (Fig.7) did not differ in the diabetic patients and non-diabetic subjects $\left(12.6 \pm 3.4\right.$ vs $\left.7.6 \pm 1.6 \mu \mathrm{mol} \cdot \mathrm{kg}^{-1} \cdot \mathrm{min}^{-1}, p=0.27\right)$.

\section{Discussion}

In the absence of an appropriate increase in plasma insulin concentration, people with Type I diabetes commonly experience an excessive increase in glucose concentration after carbohydrate ingestion. Our experiments show that when glucose, insulin and glucagon concentrations are matched in Type I diabetic patients with relatively good chronic glycaemic con- 

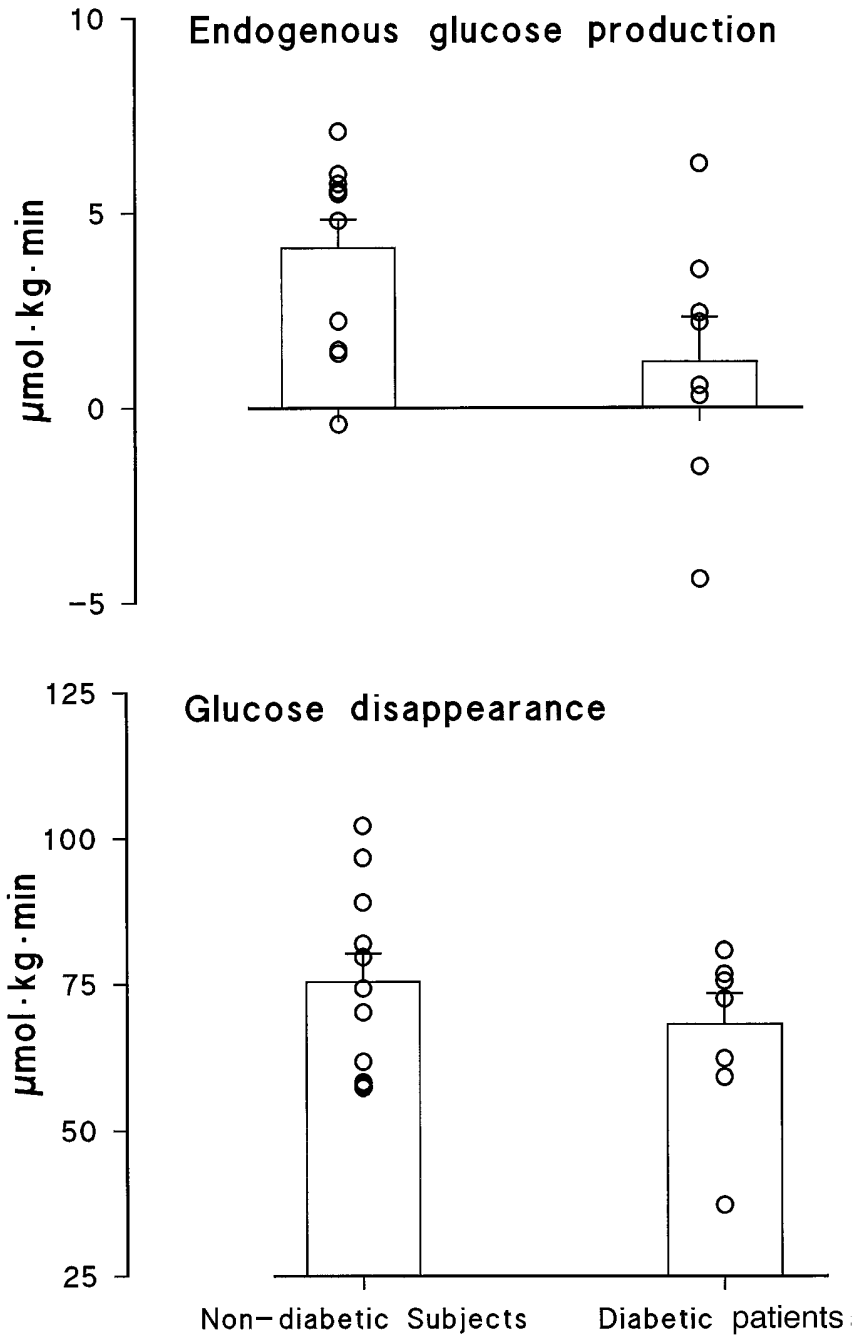

Fig.5. Rates of endogenous glucose production and glucose disappearance observed during the study. Open circles $(\bigcirc)$ represent individual subjects

trol (i.e. mean $\mathrm{HbA}_{1 \mathrm{C}}$ equal to $7.5 \%$ ), initial splanchnic glucose extraction, UDP-glucose flux (an index of hepatic glycogen synthesis) and total body glucose disappearance do not differ in diabetic patients and non-diabetic subjects during enteral glucose treatment. These data indicate that relative insulin deficiency or glucagon excess, or both, rather than an intrinsic defect in splanchnic glucose metabolism are the primary causes of postprandial hyperglycaemia in people with poorly controlled Type I diabetes.

The amount of glucose that reaches the systemic circulation after ingestion of carbohydrate depends on multiple factors including the completeness of absorption, the extent of metabolism of glucose by the gut and the rate of extraction of glucose by the liver $[4,6,7,38]$. The dual tracer approach used in our experiments measures the net effect of all three of these processes. Therefore the lack of difference in splanchnic extraction of enterally infused glucose does not necessarily mean that all of these processes
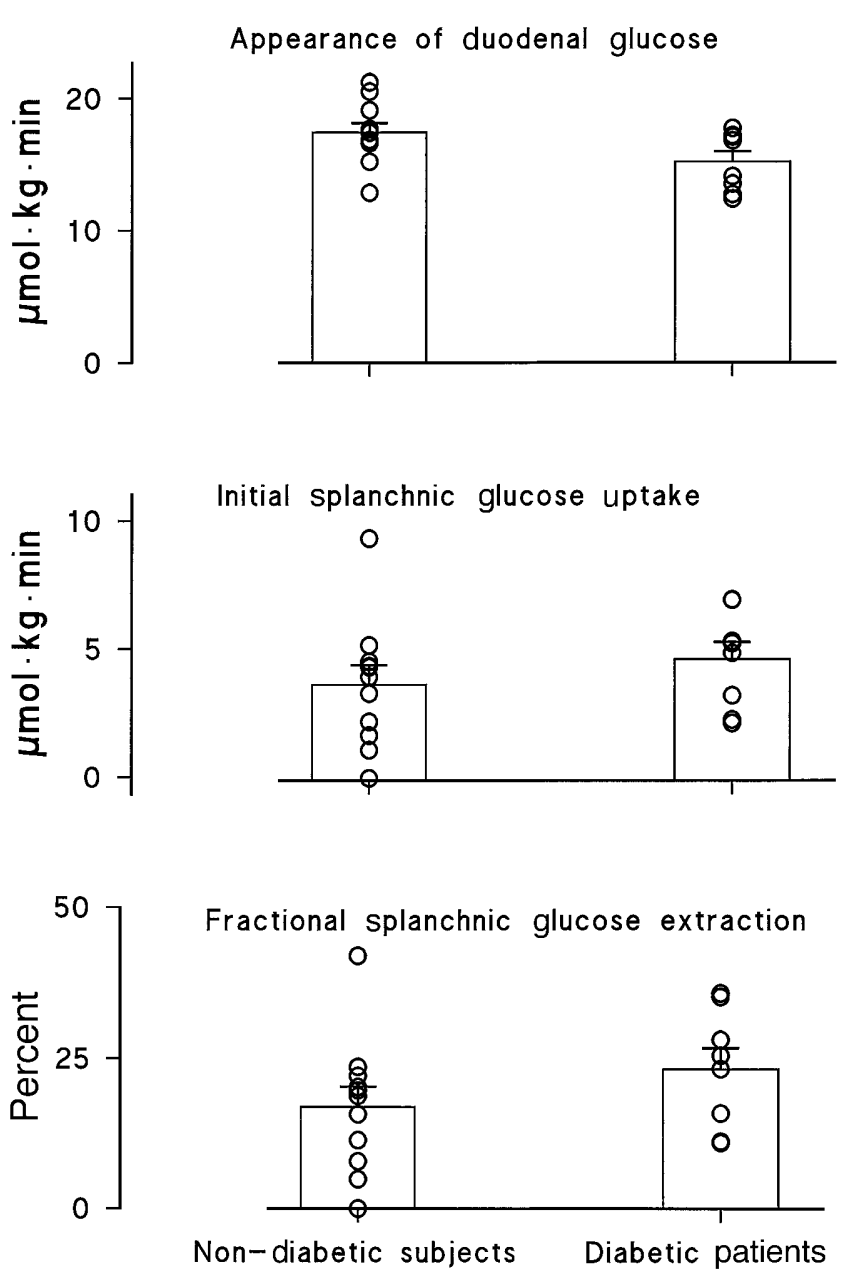

Fig. 6. Rates of meal appearance, initial splanchnic glucose uptake and fractional splanchnic glucose extraction observed during the study. Open circles $(\bigcirc)$ represent individual subjects

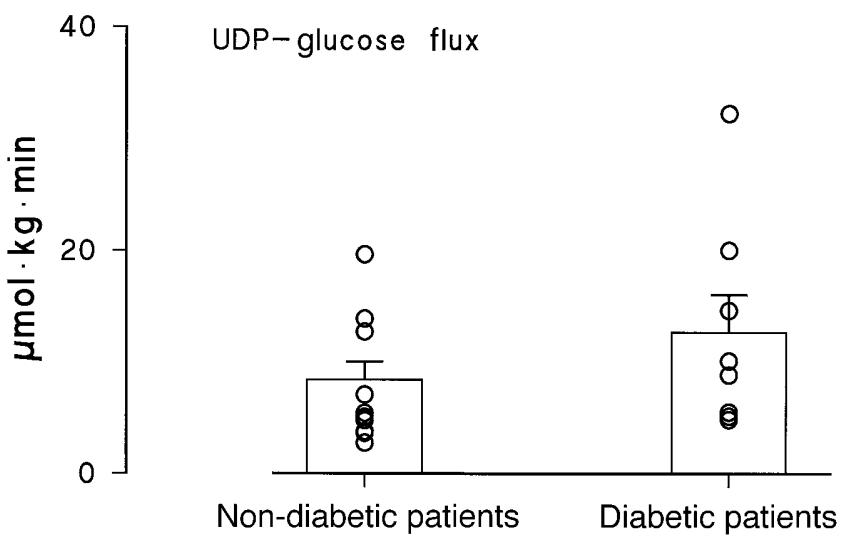

Fig. 7. Rates of UDP-glucose flux observed during the study. Open circles $(\bigcirc)$ represent individual subjects

were normal since offsetting changes could have occurred. For example, an increase in hepatic glucose extraction in the diabetic patients could have been accompanied by a proportionate increase in intestinal glucose absorption. 
Table 1. Clinical characteristics of study participants

\begin{tabular}{lll}
\hline & $\begin{array}{l}\text { Non-diabetic } \\
\text { subjects }\end{array}$ & $\begin{array}{l}\text { Diabetic } \\
\text { patients }\end{array}$ \\
\hline Sex: men/women & $8 / 3$ & $6 / 1$ \\
Fasting C-peptide $(\mathrm{nmol} / \mathrm{l})$ & $0.16 \pm 0.01$ & $<0.003 \pm 0.0^{*}$ \\
Age (years) & $36.3 \pm 3.2$ & $40.1 \pm 2.8$ \\
Body mass index $\left(\mathrm{kg} / \mathrm{m}^{2}\right)$ & $27.4 \pm 1.0$ & $26.0 \pm 0.7$ \\
Hb A $_{1 \mathrm{c}}(\%)$ & $5.2 \pm 0.2$ & $7.5 \pm 0.5^{*}$ \\
\hline
\end{tabular}

$* p<0.01$

Studies in animals suggest that chronic hyperglycaemia can lead to intestinal hypertrophy and increased glucose absorption [19, 20]. It is currently not known whether similar changes also occur in humans with chronic hyperglycaemia. Enhanced intestinal absorption could lead to an apparent decrease in splanchnic glucose extraction in the diabetic patients, especially when compared with non-diabetic subjects with incomplete absorption. However, under the conditions of this experiment (i.e. glucose infused at a constant rate directly into the duodenum for $4 \mathrm{~h}$ before measurement of extraction) it is likely that near complete absorption occurred in both groups. Furthermore, enhanced glucose absorption would have to have been offset by increased intestinal glucose metabolism or increased hepatic glucose uptake, or both, in order for there not to be a difference in net splanchnic glucose extraction. The comparable rates of UDP-glucose flux (and by implication, hepatic glycogen synthesis) in both groups argue against but do not totally exclude the latter possibility since glycolysis and lipogenesis still could have been higher in the diabetic than in the non-diabetic subjects.

There are now extensive data indicating that the enteral or portal glucose delivery results in greater hepatic glucose uptake than does intravenous infusion of a comparable amount of glucose [18, 39-43]. This so-called "portal" signal seems to be mediated by the vagus nerve in that it can be mimicked by cholinergic stimulation [40] and ablated by hepatic vagal denervation [44]. The observation that rates of UDP-glucose flux were comparable in diabetic patients and non-diabetic subjects during enteral glucose delivery is consistent with previous reports that rates of hepatic glycogen synthesis also are comparable during intravenous glucose infusion when glucose, insulin and glucagon concentrations were matched [16]. It should be noted, however, that UPD-glucose flux provides an index rather than a quantitative measure of hepatic glycogen synthesis [45, 46]. At least in theory, a portion of intrahepatic UDP- $\left[{ }^{14} \mathrm{C}\right]$ galactose can be directly converted to $\left[{ }^{14} \mathrm{C}\right]$ glucose1-phosphate without first passing through glycogen [45]. UDP-glucose flux then would exceed the rate of hepatic glycogen synthesis. However, this overestimate would probably be small under the conditions of our experiments (i.e. sustained hyperglycaemia and hyperinsulinaemia), when glycogen synthesis is occurring and the net flux of glucose-1-phosphate is into glycogen. Under these conditions most, if not all, of $\left[{ }^{14} \mathrm{C}\right]$ glucose-1-phosphate formed directly from UDP- $\left[{ }^{14} \mathrm{C}\right]$ galactose presumably would re-enter the UDP-glucose pool and be converted to glycogen. Taken together, these results indicate that the decrease in hepatic glycogen synthesis after meal ingestion, observed previously in poorly controlled diabetic patients was due to relative insulin deficiency or glucagon excess, or both, rather than due to an intrinsic defect in portal signalling in Type I diabetes [15].

Since the subjects in our experiments were screened for changes in gastrointestinal function, those with symptomatic autonomic neuropathy could be excluded. Nevertheless, it remains to be determined whether severe autonomic neuropathy and its associated changes in vagal nerve activity impair hepatic glucose uptake and thereby decrease splanchnic extraction of ingested glucose.

The diabetic patients were infused with insulin during the night to provide for comparable glucose concentrations at the beginning of the study. Overnight insulin infusion with normalization of blood glucose concentrations improves both hepatic and extrahepatic insulin action in patients with Type I diabetes [47]. Glucose disappearance, while slightly lower in the diabetic patients, did not differ from that observed in the non-diabetic subjects. This is likely due to the relatively good chronic glycaemic control of the diabetic patients and the ability of glucose (clamped at a concentration of approximately $8.5 \mathrm{mmol} / \mathrm{l}$ in both groups) to stimulate its own uptake and to suppress its own production, which could compensate for a small residual defect in insulin action. Of interest, endogenous glucose production, while substantially suppressed in both groups, was slightly lower in the diabetic than in the non-diabetic subjects. This observation is consistent with previous reports that endogenous glucose production in Type I diabetic patients, perhaps because of chronic portal hypoinsulinaemia, could be more sensitive to the suppressive effects of insulin or glucose, or both [48, 49]. These data further support the conclusion that the excessive postprandial endogenous glucose production in people with Type I diabetes is due to insulin deficiency rather than hepatic insulin resistance $[49,50]$.

In summary, this study shows that, in humans with good metabolic control, when glucose, insulin and glucagon concentrations are matched, Type I diabetes does not alter either initial splanchnic glucose extraction or hepatic UDP-glucose flux. We conclude that intrinsic alterations in splanchnic glucose metabolism are not likely to contribute to postprandial hyperglycaemia in people with Type I diabetes mellitus.

Acknowledgements. We thank D. Burton and G. Thomforde for their help with nasoduodenal tube placement, C. Etter, 
B. Dicke and G. C. Ford for their assistance, M. Davis for assistance in the preparation of the manuscript, and the staff of the Mayo General Clinical Research Center for their assistance in carrying out the studies. These experiments were supported by grants from the USPHS (DK-29953, DK-54681 and RR00585) and the Mayo Foundation. Dr. P. Shah was supported by a research fellowship from Novo Nordisk and Dr. R. Basu by a research fellowship from the American Diabetes Association.

\section{References}

1. Wright EM (1993) The intestinal $\mathrm{Na}+$ /glucose cotransporter. Annu Rev Physiol 55: 575-589

2. Newgard CB, McGarry JD (1995) Metabolic coupling factors in pancreatic beta-cell signal transduction. Annu Rev of Biochem 64: 689-719

3. Thorens B (1996) Glucose transporters in the regulation of intestinal, renal, and liver glucose fluxes. Am J Physiol 270: G541-G553

4. Abumrad NN, Cherrington AD, Williams PE, Lacy WW, Rabin, D. (1982) Absorption and disposition of a glucose load in the conscious dog. Am J Physiol 242: E398E406

5. Lang V, Vaugelade P, Bernard F et al. (1999) Euglycemic hyperinsulinemic clamp to assess posthepatic glucose appearance after carbohydrate loading. 1 . Validation in pigs. Am J Clin Nutr 69: 1174-1182

6. Capaldo B, Gastaldelli A, Antoniello S et al. (1999) Splanchnic and leg substrate exchange after ingestion of a natural mixed meal in humans. Diabetes 48: 958-966

7. Radziuk J, McDonald TJ, Rubenstein D, Dupre J (1978) Initial splanchnic extraction of ingested glucose in normal man. Metabolism 27: 657-669

8. Magnusson I, Rothman DL, Gerard DP, Katz LD, Shulman GI (1995) Contribution of hepatic glycogenolysis to glucose production in humans in response to a physiological increase in plasma glucagon concentration. Diabetes 44: 185-189

9. Velho G, Petersen KF, Perseghin G et al. (1996) Impaired hepatic glycogen synthesis in glucokinase-deficient (MODY-2) subjects. J Clin Invest 98: 1755-1761

10. Cherrington AD, Williams PE, Abou-Mourad N, Lacy WW, Steiner KE, Liljenquist JE (1982) Insulin as a mediator of hepatic glucose uptake in the conscious dog. Am J Physiol 242: E97-E101

11. Giaccari A, Rossetti L (1992) Predominant role of gluconeogenesis in the hepatic glycogen repletion of diabetic rats. J Clin Invest 89: 36-45

12. DeFronzo RA, Ferrannini E, Hendler R, Felig P, Wahren J (1983) Regulation of splanchnic and peripheral glucose uptake by insulin and hyperglycemia in man. Diabetes 32 : 35-45

13. Petersen KF, Laurent D, Rothman DL, Cline GW, Shulman, GI. (1998) Mechanism by which glucose and insulin inhibit net hepatic glycogenolysis in humans. J Clin Invest 101: 1203-1209

14. Katz J, McGarry JD (1984) The glucose paradox. Is glucose a substrate for liver metabolism? J Clin Invest 74: 1901-1909

15. Hwang JH, Perseghin G, Rothman DL et al. (1995) Impaired net hepatic glycogen synthesis in insulin-dependent diabetic subjects during mixed meal ingestion. A $13 \mathrm{C} \mathrm{nu}-$ clear magnetic resonance spectroscopy study. J Clin Invest 95: 783-787
16. Cline GW, Rothman DL, Magnusson I, Katz LD, Shulman GI (1994) 13C-nuclear magnetic resonance spectroscopy studies of hepatic glucose metabolism in normal subjects and subjects with insulin-dependent diabetes mellitus. J Clin Invest 94: 2369-2376

17. Galassetti P, Chu CA, Neal DW, Reed GW, Wasserman DH, Cherrington AD (1999) A negative arterial-portal venous glucose gradient increases net hepatic glucose uptake in euglycemic dogs. Am J Physiol 277: E126-E134

18. Adkins BA, Myers SR, Hendrick GK et al. (1987) Importance of the route of intravenous glucose delivery to hepatic glucose balance in the conscious dog. J Clin Invest 79: 557-565

19. Fujita Y, Kojima H, Hidaka H, Fujimiya M, Kashiwagi A, Kikkawa R (1998) Increased intestinal glucose absorption and postprandial hyperglycaemia at the early step of glucose intolerance in Otsuka Long-Evans Tokushima Fatty rats. Diabetologia 41: 1459-1466

20. Burant CF, Flink S, DePaoli AM et al. (1994) Small intestine hexose transport in experimental diabetes. Increased transporter mRNA and protein expression in enterocytes. J Clin Invest 93: 578-585

21. Firth RG, Bell PM, Marsh HM, Hansen I, Rizza RA (1986) Postprandial hyperglycemia in patients with noninsulin-dependent diabetes mellitus. Role of hepatic and extrahepatic tissues. J Clin Invest 77: 1525-1532

22. Ferrannini E, Bjorkman O, Reichard GA Jr et al. (1985) The disposal of an oral glucose load in healthy subjects. A quantitative study. Diabetes 34: 580-588

23. Mitrakou A, Kelley D, Veneman T et al. (1990) Contribution of abnormal muscle and liver glucose metabolism to postprandial hyperglycemia in NIDDM. Diabetes 39: 1381-1390

24. Wajngot A, Chandramouli V, Schumann WC, Efendic S, Landau BR (1991) Quantitation of glycogen/glucose-1-P cycling in liver. Metabolism 40: 877-881

25. Hellerstein MK, Kaempfer S, Reid JS, Wu K, Shackleton $\mathrm{CH}$ (1995) Rate of glucose entry into hepatic uridine diphosphoglucose by the direct pathway in fasted and fed states in normal humans. Metabolism 44: 172-182

26. Magnusson I, Chandramouli V, Schumann WC, Kumaran K, Wahren J, Landau BR (1987) Quantitation of the pathways of hepatic glycogen formation on ingesting a glucose load. J Clin Invest 80: 1748-1754

27. Hellerstein MK, Greenblatt DJ, Munro HN (1987) Glycoconjugates as noninvasive probes of intrahepatic metabolism. I. Kinetics of label incorporation with evidence of a common precursor UDP-glucose pool for secreted glycoconjugates. Metabolism 36: 988-994

28. Shulman GI, Cline G, Schumann WC, Chandramouli V, Kumaran K, Landau BR (1990) Quantitative comparison of pathways of hepatic glycogen repletion in fed and fasted humans. Am J Physiol 259: E335-E341

29. Talley NJ, Phillips SF, Melton J 3rd, Wiltgen C, Zinsmeister AR (1989) A patient questionnaire to identify bowel disease. Ann Intern Med 111: 671-674

30. White NH, Skor D, Santiago JV (1982) Practical closedloop insulin delivery. A system for the maintenance of overnight euglycemia and the calculation of basal insulin requirements in insulin-dependent diabetics. Ann Intern Med 97: 210-213

31. Rother KI, Schwenk WF (1995) Hepatic glycogen accurately reflected by acetaminophen glucuronide in dogs refed after fasting. Am J Physiol 269: E766-E773

32. Nielsen MF, Basu R, Wise S et al. (1998) Normal glucoseinduced suppression of glucose production but impaired stimulation of glucose disposal in type 2 diabetes: evidence 
for a concentration-dependent defect in uptake. Diabetes 47: $1735-1747$

33. Rizza RA, Mandarino LJ, Gerich JE (1981) Dose-response characteristics for effects of insulin on production and utilization of glucose in man. Am J Physiol 240: E630-E639

34. Kury D, Keller U (1991) Trimethylsilyl-O-methyloxime derivatives for the measurement of [6, 6-2H2]-D-glucoseenriched plasma samples by gas chromatography-mass spectrometry. J Chromatogr 572: 302-306

35. Steele R, Wall JS, De Bodo RC, Altszuler N, Kiang SP, Bjerknes C (1956) Measurement of size and turnover rate of body glucose pool by the isotope dilution method. Am J Physiol 187: 15-24

36. Hellerstein MK, Neese RA, Linfoot P, Christiansen M, Turner S, Letscher A (1997) Hepatic gluconeogenic fluxes and glycogen turnover during fasting in humans. A stable isotope study. J Clin Invest 100: 1305-1319

37. Hellerstein MK, Munro HN (1988) Glycoconjugates as noninvasive probes of intrahepatic metabolism: III. Application to galactose assimilation by the intact rat. Metabolism 37: 312-317

38. Lang V, Bornet FR, Vaugelade P et al. (1999) Euglycemic hyperinsulinemic clamp to assess posthepatic glucose appearance after carbohydrate loading. 2. Evaluation of corn and mung bean starches in healthy men. Am J Clin Nutr 69: $1183-1188$

39. DeFronzo RA, Ferrannini E, Hendler R, Wahren J, Felig P (1978) Influence of hyperinsulinemia, hyperglycemia, and the route of glucose administration on splanchnic glucose exchange. Proc Natl Acad Sci USA 75: 5173-5177

40. Shiota M, Jackson P, Galassetti P, Scott M, Neal DW, Cherrington AD (2000) Combined intraportal infusion of acetylcholine and adrenergic blockers augments net hepatic glucose uptake. Am J Physiol 278: E544-E552

41. Hsieh PS, Moore MC, Neal DW, Emshwiller M, Cherrington AD (1999) Rapid reversal of the effects of the portal signal under hyperinsulinemic conditions in the conscious dog. Am J Physiol 276: E930-E937
42. Cardin S, Emshwiller M, Jackson PA et al. (1999) Portal glucose infusion increases hepatic glycogen deposition in conscious unrestrained rats. J Appl Physiol 87: 1470-1475

43. Hsieh PS, Moore MC, Neal DW, Cherrington AD (1998) Hepatic glucose uptake rapidly decreases after removal of the portal signal in conscious dogs. Am J Physiol 275: E987-E992

44. Moore MC, Cherrington AD (1996) Regulation of net hepatic glucose uptake: interaction of neural and pancreatic mechanisms. Reprod Nutri Dev 36: 399-406

45. Landau BR (2000) Problems with the assumed biochemical basis for estimating hepatic glycogen turnover using glucuronide formation and labeled galactose. Metabolism 49: 1374-1375

46. Hellerstein MK (2000) Dilution of secreted glucuronate from labeled galactose does measure hepatic UDP-glucose turnover and (with proper corrections) can be useful for estimating hepatic glycogen synthesis. Metabolism 49: 1375-1378

47. Fasching P, Ratheiser K, Damjancic P et al. (1993) Both acute and chronic near-normoglycaemia are required to improve insulin resistance in Type I (insulin-dependent) diabetes mellitus. Diabetologia 36: 346-351

48. Hother-Nielsen O, Vaag A, Skott P, Beck-Nielsen H (1993) Effect of hyperglycemia per se on glucose turnover rates in patients with insulin-dependent diabetes. Metabolism 42: 86-93

49. Hother-Nielsen O, Schmitz O, Bak J, Beck-Nielsen H (1987) Enhanced hepatic insulin sensitivity, but peripheral insulin resistance in patients with Type I (insulin-dependent) diabetes. Diabetologia 30: 834-840

50. Pehling G, Tessari P, Gerich JE, Haymond MW, Service FJ, Rizza RA (1984) Abnormal meal carbohydrate disposition in insulin-dependent diabetes. Relative contributions of endogenous glucose production and initial splanchnic uptake and effect of intensive insulin therapy. J Clin Invest 74: 985-991 